\title{
REVERSIBILITY AND INTERSUBJECTIVITY IN MERLEAU-PONTY'S ONTOLOGY
}

\section{BEATA STAWARSKA}

In this essay I wish to examine critically Merleau-Ponty's treatment of relations with others in the light of his ontology of the flesh. I shall argue that the uniform character of the flesh and of its dynamic principle, reversibility leads to a reduction of the inter-subjective experience of the body manifest in an encounter with another embodied person, to a form of reflexivity operative within the body proper (le corps propre). The mechanics of the process by means of which the reduction is effectuated are the following: a specific, intra-subjective experience of the body is taken as a paradigm for relations to other embodied subjects. Simultaneously, its peculiar character is effaced for the sake of producing a single explanatory theory of the flesh. Deprived of its concrete specificity, the experience of one's own body comes to provide the standard norm for intersubjective or intercorporeal relations. These appear as a mere variant of the general schema, a "special case" contained in the universal dynamic of the flesh and subsumed under the heading of bodily reversibility. As a result, the peculiarities of intersubjective as well as intrasubjective lived experiences of the body are bracketed and a single category of reflexivity is applied to autoand hetero-relations alike.

\section{$I$}

Merleau-Ponty's late philosophy reads as an ongoing, unfinished project, not only due to the author's premature death but also to the inexhaustibility of the subject, commentary on what he came to term the flesh. The flesh gets defined in the course of his fine descriptions included in The Visible and the Invisible as a prototype of Being, the original and ultimate component of all there is. ${ }^{1}$ It is therefore an ontological notion and not e. g. an anthropological concept on which to found a "Philosophy of Man." Indeed, the anonymous and a-personal character attributed to the flesh is said to have opened up Merleau-Ponty's inquiry beyond the predominant perspective of the corps propre from the Phenomenology of Perception, where the starting point for analysis is situated within the body of the subject, as different from that of objectivities. This "anthropocentric" perspective is argued by numerous commentators to have been weighed down by a subjectivistic or idealistic heritage and ultimately incapable of transcending traditional binarisms, such as subject-object and intelligibility-sensibility. ${ }^{2}$ The ontological perspective of the final work, wherein the body proper no longer provides the matrix but 
is turned into an "exemplar" of general Sensibility and an instance of the anonymous movement of Reversibility running in multiple vectors throughout the flesh is said, on the other hand, to have successfully resolved the tension between these unfounded dualisms haunting the Western philosophical tradition. Following that interpretation, The Visible and the Invisible introduces a radical turn into the trajectory of Merleau-Ponty's thinking and distances his early phenomenology of the body-subject from the later ontology of the flesh.

This interpretation of Merleau-Ponty's oeuvre calls for some clarification. First of all, Merleau-Ponty himself was well aware of the constraints imposed upon his early project by the terminology adopted notably from the idealist phenomenology of Husserl. ${ }^{3}$ Secondly, the shift from the incarnated subject to the aesthesiological body, i.e. the body defined primarily in terms of anonymous reversibility and not as a privileged vantage point onto "objects" of perception, was announced already prior to its explicit formulation in The Visible and the Invisible. Albeit still operating with the concept of the (tacit) cogito, Merleau-Ponty underlined also the anonymous character of sensible experience, long before the reversibility thesis has been made. ${ }^{4}$ Finally, the explicit ontological claims made in the final late work are in a continuum with the earlier statements on the study of phenomena. The thesis of the primacy of perception contains, albeit it does not explicate, a notion of an originary unity of Being and so reads as a constructive attempt towards establishing a phenomenological ontology: the field of perception co-involves that which is revealed (perceptual reality) and the one to whom it is revealed (perceiver) and so ontological primacy belongs neither to "subjectivity" nor to "objectivity" but to the unitary phenomenal world, theorised ultimately under the heading of the flesh. ${ }^{5}$

This being said, the explicitly ontological treatment of sensible life in terms of impersonal structures occurs only in Merleau-Ponty's final work. This deliberately ontological perspective has direct implications for the question of intersubjectivity. The anonymous structure of sensibility of which my and other bodies are exemplars naturally resolves the "problem of the Other" haunting the perspective of transcendental constitution in phenomenology: the existence of alter egos ceases to be a contradiction as soon as the starting point of ego cogito is abandoned for the sake of a more originary dynamic of reversibility manifest in the lives of sensible/sentient beings. ${ }^{6}$ A problem to be resolved in turn within this radically impersonal perspective, however, might be of how to theorise persons or account for non-identical subjectivities copartaking in the dynamic of the flesh without disappearing in it. Phrased differently, a new dilemma faced by the ontology of the flesh could be that of a plurality of independent selves, without which it would make little sense to speak of relations between I and other. If we 
posit an originary stage of non-differentiation I-other, we cannot even formulate the question of intersubjectivity. Hence it has been observed that Merleau-Ponty's model "rather than solving the problem of intersubjectivity, threatens to dissolve it by annulling every plurality."

These lines voice a concern that, if reversibility is to explain - as it does how different embodied selves communicate, it should explain also how different selves arise or how the germ of self-other differentiation is contained already in pre-reflective anonymity. I contend, however, that if there is a difficulty inherent in the "intersubjective relations" model from the ontology of the flesh, it lies more specifically in its being derived from a subjective perspective and being indebted to the vécu of the body proper. The difficulty would be found less in Merleau-Ponty's procedure of "annulling" a diversity of bodily subjects and "dissolving" the problem of intersubjectivity than in his constructing the extra-subjective relation on the basis of the subjective body dynamic and locating the intelligibility of inter-corporeal life within an intracorporeal experience. In view of substantiating this thesis, I begin by citing some of Merleau-Ponty's examples of reversibility manifest within as well as between bodies. Consider first the often-cited case of the body proper relating or returning to itself, as in the example of touching the hand which palpates environing objects with the other hand (VI, 176;133). When my right hand comes into contact with the left hand palpating something, its activity easily reverses into the passivity of an organ being touched by the other hand. At the crossroads of touching and of being touched, my sensible body manifests itself both as a tactile "agent" and a "patient," distributing active and passive roles among different bodily parts.

The same compresence of tactile activity and passivity is unveiled in a body-to-body encounter with another person, e.g. in shaking hands. When my bodily organ touches an organ belonging to the body of another person, or more specifically, when the other returns my handshake, my shaking hand is being shaken as well and the activity of touching is present together with the passivity of being touched. It follows that the handshake exhibits the same kind of reversibility that is manifest within the sensible dynamics of my own body, and that the latter provides a ready model for the former. "La main d'autrui que je serre est à comprendre sur le modèle de la main touchante et touchée." "The handshake too is reversible, I can feel myself touched as well and at the same time as touching." (VI, 187; 142).

The handshake seems to extend the sentient sensibility of a carnal autorelation onto a relation with another incarnated self. The other person appears to turn the intra-corporeal reversibility of my right hand touching the left hand into an inter-corporeal exchange, playing out the reversal of touching and being touched between two bodies. In a direct reference to Husserl, ${ }^{9}$ Merleau-Ponty notes that my body accomplishes "a sort of 
reflection" when I touch myself touching. Now, when I shake the hand of another man, "his hand is substituted for my left hand" (PS, 168, emphasis added). The hand of the other takes the place of the organ belonging to my body and leaves the nature of the reflexive relation unaffected. In a handshake, my body merely "annexes the body of another person in that "sort of reflection" it is paradoxically the seat of" (ibid.). The paradox of reflection applies therefore to contacts of skin surface within the limits of the body proper as well as to contacts with other tactile bodies. After all, the touching-touched moment enacted between my two hands is said to provide the model for every reflection. ${ }^{10}$

Note that the natural divide between the body of the other and my own does not prevent the "annexing" or functional in-corporation of foreign organs into my sensible system from taking place. For there is no need to assume that there is "some huge animal whose organs our bodies would be" (VI, 187; 142) in order to account for the reversal of touch across discrete bodily beings. We need not be one body in order to be of one flesh; reversibility is a carnal auto-relation operative within the flesh as a whole, where my body and the body of the other "are like organs of one single intercorporeality" (PS, 168).

Focusing on the category of "one single intercorporeality," of which the body proper is an element but for which it does not provide a starting point of analysis, Merleau-Ponty follows here the aforementioned line of renouncing the anthropological or psychological perspective in favour of an ontological one. My body and other bodies (whether celestial or of other persons, plants, vehicles) are viewed in terms of their belonging to the whole of Being or Flesh, governed by the principle of reflexivity. As stated in a working note, "the flesh is a mirror phenomenon" (VI, 309; 255) and the phenomenon of reflecting, doubling, mirroring, is an ontological and not a psychological category. At the same time, reflexivity or mirroring gets derived from the auto-relation at work in the body proper nevertheless: "the mirror is an extension of my relation with my body" (Ibid.). One may wonder, however, whether the procedure of unqualified extending of the reversibility of $a$ body or the body proper onto the Flesh and its intercorporeality is valid and justified. Is not the dynamic of reversibility intrinsically confined to the limits of the sensible organisation of the body proper? Does not the exercise of reversibility define the limits of the sensible/sentient body and draw the border between the body proper and alter bodies? A passage from Zahavi's reading of Husserl will help to develop that point. ${ }^{11}$

If we first examine the case of one hand touching the other [the hand of the other], the touching hand $[. .$.$] has a series of sensations which are objectified and interpreted as being$ properties of the touched hand [...]. When I touch my hand, however, the touched hand is not given as a mere object, since it feels the touch itself, and this sensing does not belong to the touched hand as an objective property, but is localised in it as an Empfindnis. The 
decisive difference between touching one's own body and everything else, be it inanimate objects or the bodies of Others, is that it implies a double-sensation. The relation between the touching and the touched is reversible, since the touching is touched, and the touched is touching. It is this reversibility that testifies that the interiority [the body felt from inside] and the exteriority [the body surface] are different manifestations of the same [body]. (p. 107).

These remarks certify that the reversibility of tactile sensations applies exclusively to the sensible dynamic of a unique body and that it can be witnessed in the body proper only. The tactile sensation can be double i. e. co-involve active (touching) and passive (touched) aspects within the same living body only, since, negatively spoken, it does not suffice that the passivity be experienced as an "objective property" of the hand being touched (i.e. the hand of the other) and which one does not feel within one's sensible body. In that case, the duplicity of tactile sensations would have to be read as a split between subjectivity and objectivity and not as an essential interrelation of two distinguishable yet non-opposable sides of one sensible phenomenon. Activity and passivity would be compresent yet the tactile sensation would not be double. For the same reasons, passivity cannot be a mere effect of the activity exerted upon my body by the other with whom I shake hands, even though in this case "I feel myself touched as well and at the same time as touching." The compresence of the touching and touched moments alone does not guarantee that touch is experienced under its double or reversible character.

The sensation is double/reversible due to its anchoring in bodily organs of sense, from which the sensible movement originates (touching hand) and to which it can return (hand being touched). It is through the localisation of the bodily organ within the totality of the sensible body, gained through the feedback from the hand being touched (and missing in case of touching the hand of somebody else where the touch does not localise the touched as the same (body) but as other), that the tactile sensation is experienced as double/reversible. Put more generally, senses are bound to organs, even though they cannot be identified with them. Tactile duplicity is situated within the bodily organ-isation; it is localised in bodily organs of sense, themselves double or reflexive, sensible and sentient. The duplicity of activity/passivity is the attribute of $a$ body and of $i t s$ sensibility.

As localised in the (reflexive) body, sensations can be identified as mine. The reflexivity of sensations means that the activity of sensing is referred back to the organ and that the organ is aware of itself as it palpates something other. A hand, and generally a body, is aesthesiologically given both under a genitive and a dative form, i. e. it can be given to itself in touch and in sensibility. Double sensation is a form of self-awareness on the part of the sensing body, which guarantees that the sensing is experienced under the form of mineness and not as an anonymous event. Reversibility is both the 
principle of reflexivity of the senses and of self-reference of the individual sensing body.$^{12}$ Henceforth, it can be experienced and belongs to the sensibility of the body proper and does not extend in an automatic and unmodified fashion onto intercorporeality at large.

\section{II}

Let me now examine the structural character of a handshake in order to bring to light its difference from touching oneself, and further question Merleau-Ponty's extension of the intra-bodily experience onto the domain of the inter-body. Recall that Merleau-Ponty states that when I shake hands with someone, their hand is simply "substituted" for my hand and that their activity "substitutes" the activity of my touching hand. Yet there are valid reasons for putting forward the contrary claim that the bodily relation I hold with myself is significantly different from the relation I hold with another embodied person.

Surely I can touch myself just as I can touch and be touched by the other. Yet even though I can align my hands to make the sign of an "amen" or appraise a performance by clapping my hands together, I cannot shake hands with myself, no matter how I would twist and turn my arms. My left hand is a mirror image of the right one, just as, the left side of my visible body mirrors the right side. Needless to say, the mirroring enacted between the body sides is approximate; seeing a photographic collage where one side of my face merges with its exact mirror image can produce a bizarre effect and remind me that the natural symmetry is imperfect. Still, my body remains a "mirror phenomenon": it forms an open diptych where one volet is a more or less accurate reflection of the other one; the mirror facing my body provides a reflection of the entire bodily diptych. My body mirrors itself "before" it has been faced with the instrument of the mirror; it is a seat of living reflection independent of the reflection appearing on a smooth surface of a speculum. Now, returning to the example of a handshake, that means that shaking hands with myself is structurally as "impossible" as shaking hands with my mirror image, assuming that the phantom I see in front of me could turn to flesh and blood one day.

The phenomenon of mirroring taking place between the sides of my body is certainly not identical to the mirroring of the body in the instrument of the mirror. Even though my left hand is a "mirror image" of the right one, still unlike the phantom organ reflecting my right hand in the mirror - it is an organ with a reality of its own. My left hand is determined as being on the left side of my body, the (reflection of my) right hand in the mirror remains determined as right. My right hand reflected in the mirror remains right even though for the phantom that I see in front of me, the position of the hand would have to be reversed. From the phantom's point of view - if there was 
to be one - the hand would be determined as (belonging to the) left (volet of the body). Yet when I look at myself in the mirror, it is my bodily perspective that determines what is right and what is left. If the idea of shaking hands with the phantom does not even "cross my mind," it is because my bodily perspective is monopolistic in this case and I do not allow for an independent bodily perspective for which bodily organs could be determined as left or right. The phantom does not have a right hand that I could embrace with my right hand in a handshake. In an analogous way, my right hand cannot embrace my other real hand in a handshake. For my left hand, enlocked in the internal mirror of my body-diptych and subject to its specular logic of symmetrical parallelism is a living reflection but not a living duplicate of the right hand. Only the other person can transcend this internal bodily reflection, breaking the mirror of my body with their hand. It follows that the other can not be "annexed" in the mirror play enacted already within the spectacle of my body; or, to inverse the famous slogan, that l'homme n'est pas miroir pour l'homme. ${ }^{13}$

I cannot, in the manner of the biblical Adam, make another embodied human grow out of a part of my body and so I cannot produce a handshake from within my corporeal existence. For even though the organs of the "small animal" that I am can touch themselves, they cannot greet themselves. To greet (shake hands, but also embrace or kiss) is to welcome another "animal", to send out my organ (hands, lips) towards them and to meet the organ sent out from their alter body. A handshake does more than merely enlarge the field of my auto-reflecting body: it involves an exchange across two bodies that could not be realised independently in either of them, a new event of inter-corporeal "reversal" of greeting and being greeted unknown to the intra-corporeal reversibility of a body touching itself.

\section{III}

Let me not create a false impression that touching oneself is a solitary event devoid of any intersubjective significance. On the contrary, it reveals to me my body as a tactile thing given both to my activity and to the activity of the other. The tactile body that I am is a public thing, taking me right from the start into the realm of public relations, i. e. relations with other touching and tactile subjects. Yet insofar as $I$ am the public body that the other can touch, I remain, as Merleau-Ponty put it, always "on the same side of my body" (VI, 194; 148). I remain on the same side of the hand that greets the other but cannot greet itself for it cannot go to "the other side" of the body, the side of the body of the other with whom I shake hands. It is this inalterable situation in the body of mine that prevents the reversibility I experience when my compresent hands touch themselves from fusing with the reversibility I live when I touch and am touched by another person. It is 
the unique vantage point of my body that prevents me from adopting the vantage point of the other and grasping the passivity of my hand being touched as the activity of the other touching hand. What distinguishes the intercorporeal relation from the intracorporeal one is that the passivity of my hand touched by the other - unlike the passivity of my hand that I touch cannot reverse into an activity (of touching) for me, even though I can respond to the other touching me by touching them in turn. The break between my body (the body proper) and the body of the other separates two irreducible forms of bodily experience and makes it impossible to theorise reversibility as a uniform category applicable to the flesh as a whole.

Still, for Merleau-Ponty, the reversibility of the flesh is one, whether considered in the midst of the bodily being that $I$ am or in my relations to an embodied other. Merleau-Ponty exemplifies the category of reversibility with a case of a return to the self, such as touching the body which palpates something. This specific example might have led him to theorise reversibility in terms of a deflection or reflection of activity exerted upon the world back onto the body, and to subsume the activity of the other person exerted upon me under this pre-existent auto-reflective relation. Whether I act on my own body (touching the palpitating hand) or whether it is the other person that acts upon me (handshake), in both cases the passivity of being touched stands for the obverse or the reverse of the activity of touching (of my other hand or the hand of the other). The reversibility of the senses, e. g. touch, can be argued therefore to implicate a unique sensible "movement" running through the body and the flesh. ${ }^{14}$ Passivity of the body sentient equals sensible activity "moving in the opposite direction"; henceforth, passivity can always be reversed into activity, even if its source were other than my (reversible) body. Reversibility between activity and passivity can therefore be applied to inter-personal relations and to auto-relations alike.

Yet the identification of bodily auto-relations and relations between bodies both runs the risk of forgetting that I am situated in a concrete body which constitutes my unique point of view and is reductive of the alterity of another person, whose point of view is by definition cut off from me. The uniform notion of reversibility is based on the presupposition that passivity is by definition the reverse of activity whether or not the reversal can actually take place. We witness here an imperceptible shift from the phenomenologically valid account of reversibility in intra-corporeal life to the metaphysical principle stipulating that a reversal between activity and passivity must de jure be possible. The resulting general category of sensible reversible movement rejoins a scholastic principle of identity between actions and passions, espoused by e.g. Descartes. According to this principle, actions and passions are ultimately one, in that their movement involves a unique trajectory to be traversed from the side of the motor to the 
mobile or in the inverse or reverse direction. Depending on whether the viewpoint of the motor or the mobile is adopted, the same movement appears as active or passive. ${ }^{15}$

Note that this definition of actions and passions adopts the point of view of an impersonal (or anonymous) spectator, not situated in a unique and unchanging bodily perspective but able to move freely between the two poles of the movement. This detached spectator could regard e.g. a handshake both from the side of the person with whom I shake hands and from my side, and thus would, hypothetically at least, be able to view the passivity of my hand being touched by the other as an activity of touching for the other. This detached spectator could subsume the unique movement of sentient sensibility operative in a body-to-body encounter with another person under the phenomenon of touching one's own body, and declare that the reversibility of activity and passivity at work in inter-corporeal life is indistinguishable from the reversibility of active and passive roles played by one body sensing itself.

This impersonal spectator could therefore arrive at the thesis of uniform reversibility of the flesh that Merleau-Ponty upheld. It seems, however, that the uniform character of this thesis is its drawback rather than its advantage in that it conflates a variety of non-identical phenomena for the sake of producing a single explanatory theory of carnal life. We witness here a collapse into the universal of both subjective and intersubjective body-tobody situations, wherein the particularity of each is bracketed but for which it is the lived experience of the body proper in the tactile reversibility of double-sensations and in the reflexivity of specular symmetrism than continues to provide the norm. At the same time, the normative character of the body proper gets obscured within the context of fleshly anonymity: the principle of reversibility/reflexivity survives but it gets dislodged from its locus naturalis and ceases to apply to the subjective body experience only.

I conclude therefore that the argument for anonymous reversibility operative within the flesh and described in the Visible and the Invisible is inspired primarily - and for good reasons! - by the first person lived experience of the body and that - even though prevalent interpretations suggest the contrary - it remains indebted - again, for good reasons - to the "anthropological" perspective espoused in the Phenomenology of Perception. Rather than annulling subjectivity (and intersubjectivity), it takes the form of a generalisation and universalisation of the specific relation the body proper holds with itself and it models the account of intersubjective relations on this intra-bodily dynamic. Nevertheless, as I have argued in this essay, bodily reflexivity can apply solely to a specific subjective experience and the "logic of the mirror" cannot govern intra- and inter-corporeal relations at once. The task at hand is naturally to investigate the inter-corporeal experience of the 
body in its particularity. The author would turn to Sartre's account of the experience of the body under the gaze of the other person from Being and Nothingness for that purpose. ${ }^{16}$ The experience of the body before the other is argued there to be irreducible to the experience of the body for the self, offering us a clue towards establishing the distinction between intra- and inter-subjective dimensions of embodied experience.

Turning to Sartre for illumination on Merleau-Ponty's treatment of intersubjectivity, however, would require also reckoning with the valid criticisms the latter addressed against the dialectic system elaborated by the former and raising the question of whether the terminology of the flesh could ever be reconciled with the dualistic categories of Sartre's ontology. ${ }^{17}$ After all, is not Merleau-Ponty's final work a culminating point of his concerted effort towards overcoming the exclusive dualism of immanence and transcendence? Did he not criticise in his early texts this dualistic reality model which provides a common battle-ground for the debate between intellectualism and empiricism, where the immanent life of the subject is accorded ontological priority by the intellectualist camp, whereas the transcendent reality is granted ontological priority by the empiricists? Did he not demonstrate that a similar bifurcated reality model orients Sartre's ontology of being and nothingness? Merleau-Ponty's late ontology arose as an alternative to this "bad ontology." It should be noted, however, that Sartre's turn away from pure phenomenology to ontology was motivated by a similar contention that neither transcendence nor immanence should have ontological priority. Hence Sartre's move beyond the sphere demarcated by the immanental life of consciousness to encompass what is radically transcendent to it (the inert, opaque, resistant being or en-soi)..$^{18}$ Surely, that does not lead to overcoming the polarised reality model and resolving the tension between immanence and transcendence: Sartre dialectically rejoins the two poles of the opposition without questioning the foundations of the dualism. Despite the intention to arrive at a unitary ontology, his thinking fails therefore to account for the original unity of being - this is evident, for example, in the ontological disjunction Sartre introduces between the subjective/private and objective/public facets of the body. ${ }^{19}$ This split between the body-for-self and the body-for-others can appear incongruous with Sartre's claim that the other plays a constitutive role in the embodied existence of the self. ${ }^{20} I$ contend, however, that if Sartre overstates the case of the disjunction between the body-for others and the body-for-self, it is in view of securing the irreducibility of the intersubjective experience of the body occasioned by the encounter with another person to the subjective one and not exclusively as a result of his pervasive ontological dualism. His analysis can therefore, despite the aforementioned difficulties, provide ground for 
theorising subjectivity and inter-subjectivity as compresent yet distinct modes of bodily life and act in favour of a renewed debate between Sartre and Merleau-Ponty.

University of Louvain

\section{References}

1. Le Visible et l'invisible. Paris: Gallimard, 1964. The Visible and the Invisible. Translated by A. Lingis. Evanston: Northwestern University Press, 1968. Hereafter VI (the page number in the French text is followed by the page number in the English translation). VI, $185 ; 140$.

2. See e. g. articles included in "Recherches sur la phénoménologie de Merleau-Ponty," in Notes de Cours sur l'Origine de la géométrie de Husserl. Paris, Presses Universitaires de France, 1998. Especially, I. M. Dias, "Maurice Merleau-Ponty: une esthésiologie ontologique" and R. Barbaras: "Le dédoublement de l'originaire." Barbaras notes that "Conformément au mouvement amorcé dès la Phénoménologie de la perception, la chair est généralement abordée à partir du corps propre [...]. Or, il nous semble que cette approche échappe difficilement aux catégories - sensation, mouvement, sujet, objet, etc. que l'analyse de la perception vise pourtant à dépasser, de sorte qu'il est particulièrement malaisé d'aborder le concept ontologique de chair à partir de l'étude du corps propre, voué à disparaître comme tel au profit de la Chair comme être d'indivision." (p. 289).

3. Merleau-Ponty observes in a working note that "the problems posed in [the Phenomenology of Perception] are insoluble because I start there from the 'consciousness'-'object' distinction." (VI, 253; 200).

4. As stated in the Phenomenology of Perception: "Every perception takes place in an atmosphere of generality and is presented to us anonymously...So, if $I$ wanted to render precisely the perceptual experience, I ought to say that one perceives in me; and not that I perceive. (PP, 249; 215).

5. I make use here of M. C. Dillon's Merleau-Ponty's Ontology (Second Edition), especially pp. 51-57 and 85-100. (Evanston: Northwestern University Press, 1997). The book presents a sustained argument that Merleau-Ponty's project contains an at first implicit and subsequently explicated ontology.

6. "There is here no problem of the alter ego because it is not $I$ who sees, not he who sees, because an anonymous visibility inhabits both of us, a vision in general, in virtue of that primordial property that belongs to the flesh. "(VI, $187 ; 142)$.

7. Dan Zahavi, Self-Awareness and Alterity, n. 15, p. 251. Evanston: Northwestern University Press, 1999.

8. La Nature. Notes. Cours de Collège de France. Paris: Seuil, 1994, p. 109.

9. I.e. to Husserl's "eine Art der Reflexion." "The Philosopher and His Shadow." In Signs. Translated by R. C. McCleary. Evanston: Northwestern University Press, 1964, p. 168. Hereafter PS. PS, 166.

10. "Toute réflexion est du modèle de celle de la main touchante par la main touchée." (VI, $257 ; 204)$.

11. From the chapter on "The Lived Body" in Self-awareness and Alterity (Op. Cit.).

12. For that reason Donn Welton uses reflexivity to rethink and em-body self-awareness. In e.g. the article "Touching Hands" (forthcoming).

13. Merleau-Ponty stipulates that "l'homme est miroir pour l'homme" ("man is a mirror for man"). L'Oeil et l'esprit. Paris: Gallimard, 1964, p. 34. Thus the "mirror" relation applies simultaneously to the dynamics of the flesh, to intercorporeality and to the body proper.

14. Merleau-Ponty speaks of the body sensible and the body sentient as "two segments of one singular course [...], one sole movement in its two phases." (VI, 182; 138, emphasis added). 
15. In R. Descartes.The Passions of the Soul. Translated by S. Voss. Indianapolis: Hackett Publishing Company, 1989, $\$ 1$. It is also present in Saint Thomas and Suarez (see E. Gilson, Index scolastico-cartésien. Paris: 1913).

16. L'Etre et le Néant, (Paris: Gallimard, 1943); Being and Nothingness. An Essay on Phenomenological Ontology. Translated by H. E. Barnes. New York: Philosophical Library, 1956. Henceforth EN. Especially "The Look" (292-341; 252-302) and "The Body" (342-400; 303-359).

17. Merleau-Ponty's in-depth criticism of Sartre's ontological dualism is developed in the "Interrogation and Dialectic" chapter of The Visible and the Invisible (75-141; 50-104).

18. Sartre explains in detail his motivation for renouncing the perspective of transcendental constitution in favour of a phenomenological ontology in the "Introduction" to Being and Nothingness, entitled "The Pursuit of Being" (11-34; XLV-LXVII).

19. The subjective and objective planes of bodily existence are said to be "radically distinct" and exist "on two incommunicable levels" (EN, 343; 304). (Sartre distinguishes in fact between three ontological dimensions of the body; still, the distinction into three dimensions - a point that cannot be developed here in detail - hangs on the basic dualism of the body-subject and the body-object).

20. A criticism to that effect can be found in e. g. M. C. Dillon's "Sartre on the Phenomenal Body and Merleau-Ponty's Critique," pp. 129-133. (In The Debate between Sartre and Merleau-Ponty. Edited by Jon Stewart, Evanston, Northwestern University Press, 1998.)

\section{Bibliography}

Barbaras, R. "Le dédoublement de l'originaire." Notes de Cours sur l'Origine de la géométrie de Husserl; suivi de Recherches sur la phénoménologie de Merleau-Ponty. R. Barbaras, Editor. Presses Universitaires de France, 1998.

Descartes, R. The Passions of the Soul. Translated by S. Voss. Indianapolis: Hackett Publishing Company, 1989.

Diaz, I. M. "Maurice Merleau-Ponty: une esthésiologie ontologique." Notes de Cours sur l'Origine de la géométrie de Husserl; suivi de Recherches sur la phénoménologie de Merleau-Ponty, R. Barbaras, editor. Presses Universitaires de France, 1998.

Dillon, M. C. Merleau-Ponty's Ontology (Second Edition). Evanston: Northwestern University Press, 1997.

Dillon, M. C. "Sartre on the Phenomenal Body and Merleau-Ponty's Critique." The Debate between Sartre and Merleau-Ponty. Edited by Jon Stewart, Evanston, Northwestern University Press, 1998.

Gilson, E. Index scolastico-cartésien. Paris: 1913.

Merleau-Ponty, M. Phénoménologie de la perception. Paris: Gallimard, 1945. Phenomenology of Perception. Translated by C. Smith. London: Routledge, 1994.

Merleau-Ponty, M. "The Philosopher and His Shadow." Signs. Translated by R. C. McCleary. Evanston: Northwestern University Press, 1964.

Merleau-Ponty, M. The Primacy of Perception. Edited by J. M. Edie. Evanston: Northwestern University Press, 1964.

Merleau-Ponty, M. L'Oeil et l'esprit. Paris: Gallimard, 1964. "Eye and Mind." Translated by C. Dallery. The Primacy of Perception. Edited by J. M. Edie. Evanston: Northwestern University Press, 1964.

Merleau-Ponty, M. Le Visible et l'invisible. Paris: Gallimard, 1964. The Visible and the Invisible. Translated by A. Lingis. Evanston: Northwestern University Press, 1968.

Merleau-Ponty, M. La Nature. Notes. Cours de Collège de France. Paris: Seuil, 1994.

Sartre, J. P. L'Etre et le Néant. Paris: Gallimard, 1943. Being and Nothingness. An Essay on Phenomenological Ontology. Translated by H. E. Barnes. New York: Philosophical Library, 1956.

Welton, D. "Touching Hands" (forthcoming).

Zahavi, D. Self-awareness and Alterity. Evanston: Northwestern University Press, 1999. 